\title{
Research on the mode of competition education
}

\author{
Huang Jian \\ Xijing University, Xi’an 710123, China \\ 565200245@qq.com
}

Keywords: The first class; competition education; hands-on ability

\begin{abstract}
This paper studies and probes into the mode of competition education. Competition is very common among students of all levels, especially among college students. The purpose of the competition is to train students' ability to analyze and solve problems. It is very beneficial to cultivate students' interest and practice ability, which is an effective complement to the first class. Students participate in the competition, help to improve their ability, to the future development and to society are of great help. Competition education is a good method of teaching reform.
\end{abstract}

\section{Introduction}

The overall construction idea is the project 2-BO6 single chip microcomputer principle and application laboratory as the platform, through the training of students' project, to train students' innovative practice ability. Carry out the second class, second class organization as an important position of practice teaching, in order to strengthen the practical teaching and electronic experimental courses, schools and departments have invested a certain amount of funds to support the purchase of laboratory supplies, equipped with some advanced instruments and equipment.

Research method is "project training method", the project can come from the previous National Undergraduate Electronic Design Contest title, graduation project title, teacher's research projects, etc.. All these belong to the category of teacher's proposition. Through this platform, teachers' scientific research ability can also be improved.

\section{Implementation measures}

The project implementation plan is carried out in three steps: first, pre theoretical training, followed by training of designated topics, and finally, the stage of independent innovation. The concrete steps are as follows:

The project is based on the principle and application of single chip microcomputer as a pilot project. The project team members are used as guidance teachers and daily training is carried out by relying on the workshop 2-B06 laboratory. The design and implementation of the overall implementation plan by the project leader are as follows:

From 1. March $2017 \sim 5$ month, 10 students in computer science and technology, electronic information, mobile communication and other professional requirements, this part of the students must have enough interest in electronic design and has certain theoretical knowledge and strong practical ability. This stage is under the charge of teacher Fan Hui.

From 2. May 2017 6 months, under the guidance of teachers pre training theory, mainly for the following courses: "MCS-51 microcontroller principle and application", "analog electronic technology", "MSP430" principle and application of single chip microcomputer, "C programming language" theory of training courses. This stage is under the unified responsibility of teacher Fan Hui, and other teachers are responsible for the specific training courses.

from June 2017 2017 September, after the preliminary theoretical training, into the actual project production, by the guidance of teachers to develop some projects, by the students themselves team, 3 people a group, division of labor. One person is responsible for software programming, and one person is responsible for hardware debugging, and one person is responsible for welding and manufacturing. Choose a person as a team leader, when problems arise, the three 
unite and work together to solve them. Each group can choose one subject according to its own specialty, and make a final production of one or two samples. This stage is under the charge of teacher wang. The following topics can be trained:

Some industrial temperature and humidity digital transmitter

Some universal industrial temperature controller

To high and low temperature test box temperature controller

Some high precision field temperature calibration instrument

The environmental parameter tester, solar power supply mode

To multi point temperature gradient tester

Methane gas concentration monitor, intrinsically safe

Ultrasonic range finder based on it

Some ultrasonic roadway cross-section totalizer based on

First solar temperature hygrometer

From September 2017 2018 in December, into the "independent proposition" production stage, by the students themselves according to interest and hobbies, put forward specific questions, by the teacher approval after implementation. This time is the best exercise and training for students' innovative ability. First of all, the proposed topic should have some new ideas. In the process of development, we should overcome all kinds of difficulties and propose creative solutions. Specific implementation by Huang Jian and Lv Lintao teacher is responsible for.

If the project is to be carried out smoothly, the following conditions must be met:

1) there should be guidance teachers, who are in charge of the project, and all the other teachers should take part in the work, and work programs will be formulated in accordance with their respective research directions.

2) to select 10 students, students must have the following conditions: with a strong interest in electronic design, with continuous learning and fast learning ability, have hard-working spirit and firm and indomitable perseverance, have challenged the heights of science and ability to persevere.

3) teachers should possess certain scientific research strength, the project group of teachers engaged in teaching work for many years, and guide the students participated in many National Undergraduate Electronic Design Contest of college students in Shaanxi province and the TI cup (TI) analog and analog digital hybrid circuit design contest, have strong research ability and practice ability.

4) with a certain experimental condition, production base for students' daily training and project engineering workshop in the laboratory to do, the laboratory is equipped with a computer, oscilloscope, multimeter, iron and other essential conditions of experiment.

5) the school should have a certain degree of financial support, the implementation of "project for proposition" and "independent proposition project", the implementation of the project to carry out the principle of drawing, PCB, components and other supplies purchase according to the project requirements.

The project has the following promotional value:

If the project can be successfully implemented, it will build a bridge between theoretical teaching and practical teaching, and can make theoretical knowledge be applied to practice as soon as possible and form a work. It will make the second class an important supplement to the first class. It provides new ideas for the teaching reform of other courses.

From the "proposition project" and "independent proposition project", choose to make better projects for promotion or cooperate with other enterprises to produce, so as to produce certain economic benefits for schools.

For more innovative projects, can be elevated to the theoretical level, may apply for patents or published papers.

For students, through the preliminary pilot, we can train students to become innovative talents, and train them into the talents needed by society and enterprises. Among other students, further publicity can be carried out to enlarge the influence and encourage more students to participate. If 
we can continue to develop and expand, we can play a good role in promoting the style of study in schools. Make our school become "Engineering" strong school lays a certain foundation.

The research method adopts the practice teaching method, namely trains the student's innovation practice ability through the concrete project training. First of all, the "project project" training method is adopted, and the proposition project is derived from the annual National Undergraduate Electronic Design topic. Because the electronic competition topics include microcontroller programming, electronic contest questions have been carefully selected group of fine national experts, represents the development direction of the current electronic information teaching project, the guiding role of our research. Every year, electronic competition issues are relatively new, seize the forefront of science and technology. Take the 2015 electronic contest as an example, the title of control class has "wind pendulum", "four rotor aircraft", "high frequency" category, and the frequency has been raised to more than 100M. This is a challenge for teachers and students to learn to use the basic knowledge of the frontier, a relatively high degree of difficulty to solve the problem, must have innovative thinking ability and profound theoretical foundation and comprehensive application of knowledge and ability.

Through the theoretical training of students, so that they master the design of such topics. After a specific subject exercises, so that

Students' practical ability has been improved. It lays a foundation for the cultivation of creative ability.

The research group has made a comparative study of various aspects such as curriculum system, educational purpose, educational model and teaching content in our college and other institutions of higher learning. Other institutions of higher learning attach great importance to the training of applied talents, with rich teaching content, diversified teaching methods and sufficient funds input, and formed a relatively perfect training system of applied talents. The research of our school is at the beginning and exploration stage, there is a gap in the reform of teaching content, the scientific design of curriculum system and the diversification of teaching methods.

By the research group of the school and other institutions of higher learning in the training applied talents, demonstrates the importance of strengthening the application of law students' talents and urgency, strengthen the cultivation of applied talents is the call of the times, and put forward a new mode of education to strengthen the cultivation of applied talents.

\section{Summary}

Research group pointed out that the establishment of scientific and standardized operating mechanism is the fundamental guarantee for the application of talents training in Colleges and universities. Applied talents training goal oriented mechanism, perfecting the operation mechanism includes at least a school of thought of the guiding mechanism, teacher training and all kinds of security mechanisms and supervision, feedback, evaluation, incentive mechanism and social participation etc..

\section{References}

[1] Hu Yongmei, Xue Haiping. Evaluation of the impact of science competition on the scientific quality of senior high school students in China [J], educational research,.2014,9:51-60.

[2] Wang Liwei, Tian Jian. Research on Influencing Factors of innovation competition performance based on Internet community [J]. Research management,.2014,35 (2): 17-24.

[3] Du Zhen, Cao Huili, Wei Linhua, Li Cong. Relying on scientific and technological innovation competition to train applied talents [J], education research,.2013,9:153-159.

[4] Zhu Yongyong. Research on the integration and integration of vocational education skills competition and practice teaching [J], higher engineering education research,.2015,5:169-178. 